$\underline{\text { Article }}$

\title{
Large Amplitude Vibrations in the HFCIF Complex
}

\section{Stella M. Resende, Josefredo R. Pliego Jr, and Wagner B. De Almeida}

\author{
Laboratório de Química Computacional e Modelagem Molecular, Depto de Química, \\ ICEx, UFMG, 31270-901 Belo Horizonte - MG, Brazil
}

Received: January 1, 1997

\begin{abstract}
Os movimentos de grande amplitude no complexo $\mathrm{HF} \cdots \mathrm{ClF}$ foram estudados teoricamente. $\mathrm{Na}$ solução das equações dinâmicas foi utilizada uma superfície de energia potencial $a b$ initio calculada a nível MP2/DZ+(2d1f/2p1d)//HF/DZP, incluindo a correção para o erro de superposição do conjunto de bases (BSSE). A frequiência para o estiramento da ligação de van der Waals e a frequiência e a intensidade da deformação $\mathrm{HF}$ … Cl foram calculadas e comparadas com valores experimentais harmônicos teóricos e experimentais disponíveis. A freqüência de estiramento calculada é $97,60 \mathrm{~cm}^{-1}$, a qual está em excelente acordo com o valor experimental harmônico de $100 \pm 2 \mathrm{~cm}^{-1}$. O valor para esta frequiência incluindo a anarmonicidade é $89,38 \mathrm{~cm}^{-1}$. A freqüência fundamental calculada para a deformação $\mathrm{HF} \cdots \mathrm{Cl}$ é $13,12 \mathrm{~cm}^{-1}$, enquanto cálculos $a b$ initio considerando a aproximação harmônica prevêem um valor de $72 \mathrm{~cm}^{-1}$. Esta diferença significativa é devida ao movimento de tunelamento através do ângulo $\mathrm{HF}$... $\mathrm{Cl}$, o qual tem uma barreira para esta rotação interna de $151 \mathrm{~cm}^{-1}$. As intensidades destas transições foram calculadas em duas temperaturas. Em $10 \mathrm{~K}$, apenas a transição fundamental é significativa, enquanto que a $300 \mathrm{~K}$ uma banda quente em $81,30 \mathrm{~cm}^{-1}$, resultante de uma transição entre o terceiro e o quarto nível, domina o espectro.
\end{abstract}

The intermolecular large amplitude motions of the HF $\cdots \mathrm{ClF}$ complex were studied theoretically. The $a b$ initio intermolecular potential energy surface, calculated at the MP2/DZ+(2d1f/2p1d)//HF/ DZP level of theory including BSSE correction, was used in the solution of the dynamical equations. The frequency for the van der Waals stretching and the frequency and the intensity of the $\mathrm{HF} \cdots \mathrm{Cl}$ bending were calculated. The frequency results were compared with reported theoretical and the experimental harmonic values. The harmonic stretching frequency calculated is $97.60 \mathrm{~cm}^{-1}$, which is in excellent agreement with the experimental harmonic value of $100 \pm 2 \mathrm{~cm}^{-1}$. The frequency value calculated including anharmonicity is $89.38 \mathrm{~cm}^{-1}$. The calculated fundamental frequency of the $\mathrm{HF} \cdots \mathrm{Cl}$ bending vibration is $13.12 \mathrm{~cm}^{-1}$, while harmonic ab initio calculations predicted a value of $72 \mathrm{~cm}^{-1}$. This significant difference is due to tunneling motion through the $\mathrm{HF} \cdots \mathrm{Cl}$ angle, which has a barrier to internal rotation of $151 \mathrm{~cm}^{-1}$. The intensities of these transitions at two temperatures have also been calculated. At $10 \mathrm{~K}$, only the fundamental transition is significant, whereas the hot band transition of $81.30 \mathrm{~cm}^{-1}$ between the third and fourth levels dominates the spectrum at $300 \mathrm{~K}$.

Keywords: tunneling, van der Waals complexes, spectroscopy, ab initio calculations

\section{Introduction}

Large amplitude motions are very common in van der Waals complexes, where harmonic analysis usually employed in $a b$ initio calculations may not be adequate. Rather, the use of more accurate methods is recommended to calculate the rovibrational levels and the respective transitions. In many situations, there is considerable cou- pling of rotational and vibrational motions, and the use of higher dimensional calculations is necessary. For example, in the case of the $(\mathrm{HF})_{2}$ dimer, the presence of two light hydrogen atoms leads to a tunneling motion involving the whole complex, and the coupling of the rovibrational motions is considerable. Many years have passed since this complex was first studied experimentally ${ }^{1}$, and until now several studies are still being published ${ }^{2-4}$. The $(\mathrm{HF})_{2}$ dimer 
was studied theoretically with different degrees of approximation. In 1988, Kofranek et $\mathrm{al}^{5}$ published a work where the potential energy surface for this dimer was investigated by the coupled pair functional approach. More than 1000 points were evaluated on the 6D energy surface, and the stationary points were characterized by harmonic vibrational analysis. Althorpe and Clary ${ }^{6}$ used an analytical $a b$ initio potential energy surface of Bunker et al. ${ }^{7}$, and the infra-red spectrum was predicted diagonalising the Hamiltonian for the dimer with the intra and intermolecular bond lengths held fixed. The tunneling splitting was emphasized in the work of Zhang et al. ${ }^{8}$, where a fitting of Quack and $\mathrm{Suhm}^{9}$ for the $6 \mathrm{D}$ potential energy surface of Kofranek et al. was employed in a calculation using the discrete variable representation (DVR). Their study provided a comprehensive description of the bound state properties of the $(\mathrm{HF})_{2}$ dimer and its isotopomers, including their dissociation energies, frequencies of intermolecular vibrations, tunneling splittings, and a quite complete review about the history of this dimer was presented. Necoechea and Truhlar ${ }^{10}$ published a new fitting of the potential energy surface of Quack and Sun and new quantum mechanical nine-dimensional calculations of the vibrational energy levels on this surface. The $6 \mathrm{D}$ result of Zhang et al for splitting by tunneling is $0.44 \mathrm{~cm}^{-1}$, while the 9D results of Necoechea and Truhlar is $0.65 \mathrm{~cm}^{-1}$, which is in excellent agreement with the experimental value of $0.659 \mathrm{~cm}^{-1}$. These facts show that the coupling of the intermolecular motions may be very important in the full description of the rovibrational motions in weakly bound complexes.

However, in some cases a low dimensional approximation works fairly well, as for complexes where the tunneling motion is not significantly coupled with other intermolecular modes. Four good examples are the $\mathrm{C}_{2} \mathrm{H}_{4} \cdots \mathrm{SO}_{2}{ }^{11}$, $(\mathrm{HCCH})_{2}{ }^{12}, \mathrm{H}_{2} \mathrm{O} \cdots \mathrm{CO}_{2}{ }^{13}$ and the $\mathrm{H}_{2} \mathrm{O} \cdots \mathrm{H}_{2} \mathrm{CO}^{14}$ dimers. For the $\mathrm{C}_{2} \mathrm{H}_{4} \cdots \mathrm{SO}_{2}$ dimer, the possibilities of rotations of the two subunits were investigated using ab initio calculations, and the structural and energetic features lead to the determination of the subunit responsible for internal rotation. The tunneling motion was studied by an one-dimensional approach, and the comparison of the calculated splitting with the experimental value showed that this procedure is efficient. Although the highly dispersive character of the bonding in the $(\mathrm{HCCH})_{2}$ complex made calculations a difficult task, the use of a one-dimensional calculation followed by a two-dimensional correction is a faster and simpler procedure than the two-dimensional calculations, producing comparable results ${ }^{12}$. In the $\mathrm{H}_{2} \mathrm{O} \cdots \mathrm{CO}_{2}$ and $\mathrm{H}_{2} \mathrm{O} \cdots \mathrm{H}_{2} \mathrm{CO}$ complexes the authors used one, two and three dimensional potential energy functions to calculate the vibrational energy levels of large amplitude motions. They considered only coupling between two or three modes, and the results were found to be in reasonable agreement with the reported experimental results.
There are also several experimental works that use low dimensional approaches to describe the tunneling motions observed in the rotational spectrum ${ }^{15-18}$. For example, in their study of the HF... $\mathrm{Cl}_{2}$ dimer, Stockman and Blake ${ }^{15}$ measured the $\mathrm{HF}$... Cl bending frequencies and fitted an one-dimensional quartic-quadratic potential where the parameters were adjusted to predict the energy level splittings determined experimentally. Thus, the energy barrier for interconversion and the bending wavefunctions were obtained. The calculated energy levels are comparable with the experimentally measured values. Therefore, the low dimensional approximation is very useful in some cases and it may encompass the principal features of the large amplitude vibrations in several complexes.

Other interesting situations occur with the HF...ClF complex, which has a low energy barrier for interconversion between two isoenergetic forms that have the hydrogen atom below and above the line connecting the three heavy atoms ${ }^{19}$. Of the four intermolecular vibrational modes, the bending motion through the $\mathrm{HF} \cdots \mathrm{Cl}$ angle corresponds to a very large amplitude vibration. In their experimental work, Novick et al. ${ }^{20}$ used a harmonic pseudo-diatomic model to predict the van der Waals stretching motion and also estimated the in-plane and outof-plane F... ClF bending frequency, considering it to be degenerate. The proton in plane bending was not studied. Rendell et al. ${ }^{21}$ and De Almeida et $a l .{ }^{22}$ have performed $a b$ initio calculations using the harmonic approximation.

In a recent theoretical investigation of the intermolecular potential energy surface for this complex, Pliego et al. ${ }^{23}$ calculated the barrier for interconversion through the bending motion of the $\mathrm{HF} \cdots \mathrm{Cl}$ angle. This value was estimated to be $133 \mathrm{~cm}^{-1}$ at the MP2/DZ+(2d1f/2p1d)//HF/DZP level including the basis set superposition error (BSSE) correction, what seems low to allow a tunneling from one isoenergetic form to another.

In this article, we have studied the large amplitude $\mathrm{HF}$... Cl bending and the van der Waals stretching for the $\mathrm{HF}$... ClF dimer, using an ab initio intermolecular potential energy surface and a one dimensional treatment of internal motion. For the bending motion, we have calculated the eigenvalues and the eigenfunctions variationally, leading to the determination of the transition dipole moments and absorption intensities involving the four lowest levels. The frequency for van der Waals stretching was calculated using a fit for the potential energy surface and the Dunham expansion. These results are compared with the previously reported results.

\section{Calculation of the Intermolecular Potential Energy Surface}

The potential energy surface for the bending and the stretching motions of the HF...CIF complex were calcu- 
lated using the DZ+(2d1f,2p1d) basis set with the polarization exponents ${ }^{24}$ given in Table 1 . The electronic correlation was taken into account at the MP2 level and the BSSE correction was included using the counterpoise method of Boys and Bernardi ${ }^{25}$. All ab initio calculations were performed with the GAMESS package ${ }^{26}$. The intra and intermolecular parameters used in the calculations were obtained from the equilibrium geometries for the minimum and linear transition state anti-H bonded structures reported by Pliego et al., at the HF/DZP level of calculation. The geometrical parameters are defined in Fig. 1, and given in Table 2, along with the energy values obtained.

For the bending motion, the distance between the mass centers of the two monomers (3.406 $\AA$ ), was frozen, as well as the intramolecular bond distances $\left(R_{1}\right.$ and $\left.R_{2}\right)$. These restrictions can be justified observing Table 2 . The values of $R_{1}$ and $R_{2}$ do not alter on going from the minimum

Table 1. Polarization exponents ${ }^{24}$ of the DZ basis set used in the $a b$ initio calculations for the $\mathrm{HF} \cdots \mathrm{ClF}$ complex.

\begin{tabular}{lccc}
\hline & $\mathrm{p}$ & $\mathrm{d}$ & $\mathrm{f}$ \\
\hline $\mathrm{H}$ & $1.0,0.2$ & 0.075 & - \\
$\mathrm{F}$ & - & $1.0,0.36$ & 0.275 \\
$\mathrm{Cl}$ & - & $0.5,0.2$ & 0.17 \\
\hline
\end{tabular}

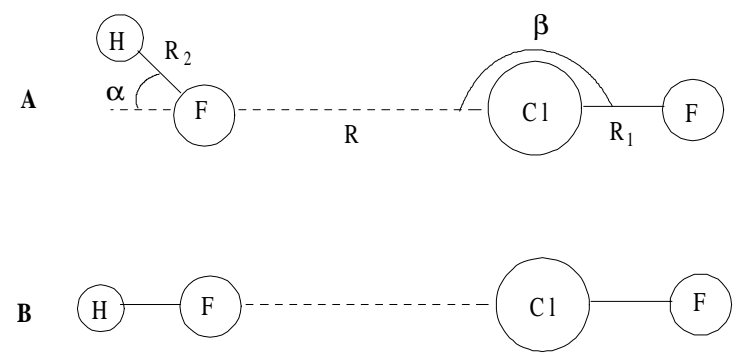

Figure 1. Schematic representation of the equilibrium minimum (A) and transition state (B) optimized structures of the anti H-bonded $\mathrm{HF} \cdots \mathrm{ClF}$ complex. energy structure to the transition state structure, and the intermolecular distance $\mathrm{R}$ changes by just 0.05 angstrom. The $\alpha$ and $\beta$ angles were varied concertedly, starting from the values in the minimum structure until those of the transition structure, performing a total of 33 points ranging from $-\pi$ to $\pi$ radians. Since the distance between the mass centers was frozen, it is smaller in our calculation than in the fully optimized transition state structure, leading to a higher energy barrier $\left(151.24 \mathrm{~cm}^{-1}\right)$. The calculated points are represented by dots in Fig. 2, for the $\alpha$ angle. This function was fitted to a polynomial form using the least squares method, resulting in:

$$
\begin{aligned}
& \mathrm{V}_{\text {bend }}(\alpha)=152.280-271.951 \alpha^{2}+147.387 \alpha^{4}- \\
& -25.387 \alpha^{6}+3.308 \alpha^{8}-0.123 \alpha^{10}-0.004 \alpha^{12}
\end{aligned}
$$

represented in Fig. 2 by a solid line. Comparing the calculated points with the fitted curve, it can be seen that there is excellent agreement. The inclusion of higher terms does not significantly alter the fitting.

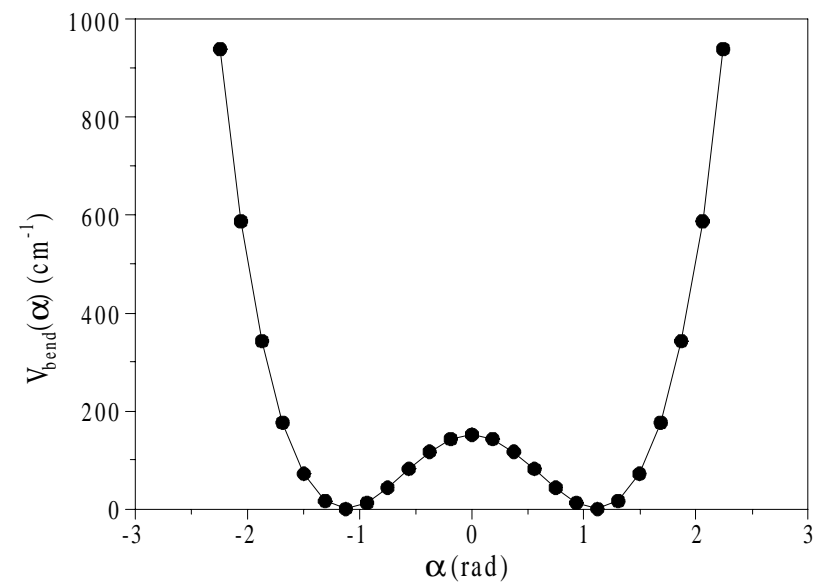

Figure 2. Intermolecular potential energy surface for the $\mathrm{HF} \cdots \mathrm{Cl}$ bending motion of the $\mathrm{HF} \cdots \mathrm{ClF}$ complex. The $\alpha$ angle is defined in Fig. 1. The dots represents the calculated points, and the solid line is the fitted curve (Eq. 1).

Table 2. Intra and intermolecular parameters and energetic values for the minimum and the linear transition state structures of the ant i-hydrogen bonded HF... ClF complex, obtained with the DZP basis set ${ }^{23}$. All energy values are BSSE corrected.

\begin{tabular}{lcc}
\hline Parameters & Minimum structure & Linear TS structure \\
\hline $\mathrm{R} / \AA$ & 2.82 & 2.87 \\
$\mathrm{R}_{1} / \AA$ & 1.61 & 1.61 \\
$\mathrm{R}_{2} / \AA$ & 0.90 & 0.90 \\
$\alpha / \mathrm{deg}$ & 54 & 0 \\
$\beta / \mathrm{deg}$ & 177 & 180 \\
$\mathrm{D}_{\mathrm{e}}(\mathrm{HF} / \mathrm{DZP}) / \mathrm{cm}^{-1}$ & -718 & -670 \\
$\mathrm{D}_{\mathrm{e}}(\mathrm{MP} 2 / \mathrm{DZ}+(2 \mathrm{~d} 1 \mathrm{f} / 2 \mathrm{p} 1 \mathrm{~d}) / / \mathrm{HF} / \mathrm{DZP}) / \mathrm{cm}^{-1}$ & -763 & -630 \\
$\mathrm{~h}(\mathrm{MP} 2 / \mathrm{DZ}+(2 \mathrm{~d} 1 \mathrm{f} / 2 \mathrm{p} 1 \mathrm{~d}) / / \mathrm{HF} / \mathrm{DZP}) / \mathrm{cm}^{-1}$ & & 133 \\
\hline
\end{tabular}


For the stretching motion, the potential energy surface was constructed by variation of the distance between mass centers, keeping the intramolecular and the remaining intermolecular parameters constant. The curve obtained is shown in Fig. 3 by the dots, and the fitted polynomial (least squares) of order six is represented in Fig. 3 by a solid line. The fitted expression is:

$$
\begin{aligned}
V_{\text {str }}(r) & =1726378.4-2445996.7 r+1440475.6 r^{2}- \\
& -451599.42 r^{3}+79519.721 r^{4}-7457.1228 r^{5}+ \\
+ & 290.39824 r^{6}
\end{aligned}
$$

Although the fitted curve do not represent the real curve in the asymptotic region, the function should work well because we are interested in the lowest eigenvalues that are deep in the well.

\section{Calculation of the Vibrational Spectrum}

The eigenvalue/eigenfunction problem for the bending motion can be solved using the variational method. The Hamiltonian is:

$$
\mathrm{H}=\frac{-\mathrm{h}^{2}}{2 \mathrm{I}_{\mathrm{HF}}} \cdot \frac{\partial^{2}}{\partial \alpha^{2}}+\mathrm{V}_{\text {bend }}(\alpha)
$$

In this approach, the wavefunction $\Psi$ is expanded in a linear combination of basis functions $\chi$ :

$$
\Psi=\sum \mathrm{c}_{\mathrm{i}} \chi_{\mathrm{i}}
$$

and the coefficients and the energies are obtained by minimizing the following functional:

$$
\mathrm{E}=\min \langle\Psi|\hat{\mathrm{H}}| \Psi\rangle
$$

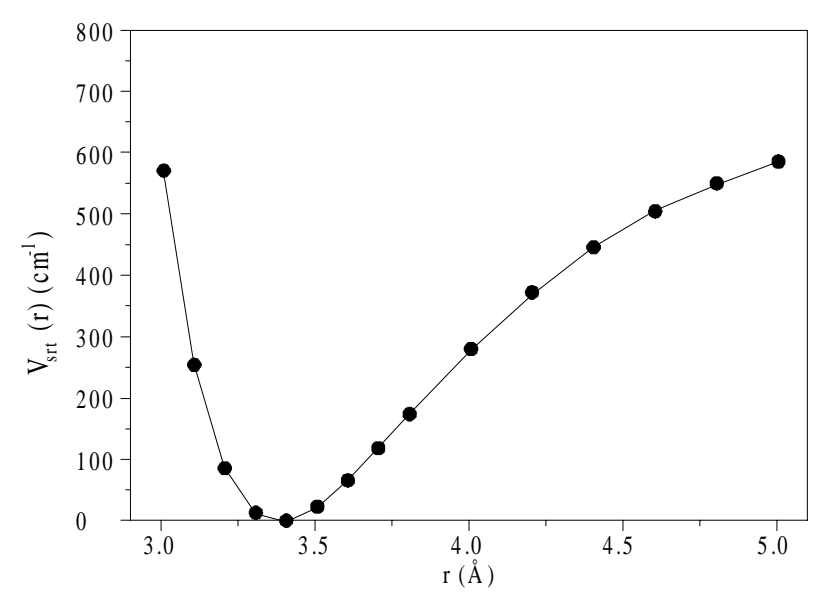

Figure 3. Intermolecular potential energy surface for the van der Waals stretching motion of the anti-H bonded $\mathrm{HF} \cdots \mathrm{ClF}$ complex. The variable $\mathrm{r}$ stands for the center of mass distance. The dots represents the calculated points, and the solid line is the fitted curve (Eq. 2).
The eigenvectors and the respective eigenvalues that minimize the functional are obtained by solving the following matricial problem:

$$
\mathrm{HC}=\mathrm{E} \mathbf{C}
$$

where $\mathbf{C}$ is the coefficients vector and $\mathbf{H}$ is the Hamiltonian matrix, with elements:

$$
\mathrm{H}_{\mathrm{ij}}=<\chi_{\mathrm{i}}|\mathrm{A}| \chi_{\mathrm{j}}>
$$

We have chosen $\chi$ to be the eigenfunctions of a particle in a box of length $2 \mathrm{a}$ to make the expansion. Owing to the symmetry of the problem, the eigenfunctions will have odd $(-)$ and even (+) symmetry. So, the wavefunction can be expanded as:

$$
\begin{aligned}
& \Psi^{-}=\sum_{i} c_{i} \frac{1}{\sqrt{a}} \sin [i \pi \alpha] \\
& \Psi^{+}=\sum_{i} c_{i} \frac{1}{\sqrt{a}} \cos [(i-1 / 2) \pi \alpha]
\end{aligned}
$$

This choice of this basis set is suitable because we are using the boundary conditions $\Psi( \pm \mathrm{a})=0$. This is a reasonable form to solve the problem because the lowest vibrational bending modes will be limited to the double well region. We have used the value of radians for the a constant, since it is the physical limit for the $\alpha$ angle in this complex. The number of basis functions $\chi$ necessary for convergence is 15 , and the eigenvalues obtained are given in Table 3, along with the coefficients for their respective eigenfunctions. The eigenvalues are shown with the potential energy surface in Fig. 4, and the eigenfunctions are in Fig. 5. The behavior of these functions near the potential wall is a test for the correctness of the value used for the a constant. It shows that before reaching $\pi$ radians the eigenfunctions are practically null. Therefore, the use of the particle in a box wavefunctions as a basis set is fully satisfactory to obtain the lowest eigenvalues for this problem.

The form of the wavefunction for these four lowest levels is consistent with the energies of each level in relation to the energy barrier. The first wavefunction of even symmetry does not present a node but has one well, which was caused by the barrier. The energy for this level is near the barrier top, and the wavefunction has a considerable penetration into the barrier. The first wavefunction of odd symmetry presents one node and two peaks. The proximity of its energy with that of the even wavefunction is an effect caused by the barrier. These functions are located in the same region, and its oscillations are close, resulting in a near-degenerescency. Increasing the barrier will lead the amplitude of wavefunction in the barrier 
Table 3. Eigenvalues and coefficients for the eigenfunctions obtained by the variational solution of the Eq. 3 with the basis set funct ions (4).

\begin{tabular}{lcccc}
\hline Eigenvalue $\left(\mathrm{cm}^{-1}\right)$ & 78.99 & 92.11 & 205.01 & 286.31 \\
Symmetry & even & odd & even & -0.0834 \\
\hline$c_{1}$ & -0.7136 & 0.9018 & -0.2798 & -0.5962 \\
$c_{2}$ & -0.6647 & 0.2728 & 0.2280 & -0.7295 \\
$c_{3}$ & -0.1587 & -0.2311 & 0.7529 & -0.2947 \\
$c_{4}$ & 0.1246 & -0.2356 & 0.5353 & 0.0800 \\
$c_{5}$ & 0.0898 & -0.0477 & 0.0542 & 0.1081 \\
$c_{6}$ & 0.0063 & 0.0308 & -0.1073 & 0.0204 \\
$c_{7}$ & -0.0109 & 0.0160 & -0.0431 & -0.0100 \\
$c_{8}$ & -0.0028 & -0.0002 & 0.0042 & -0.0039 \\
$c_{9}$ & 0.0004 & -0.0015 & 0.0049 & 0.0002 \\
$c_{10}$ & -0.0002 & 0.0003 & 0.0002 \\
$c_{11}$ & 0.0002 & -0.0002 & 0.0000 \\
$c_{12}$ & 0.0000 & 0.0000 & 0.0000 & 0.0000 \\
$c_{13}$ & 0.0000 & 0.0000 & 0.0000 & 0.0000 \\
$c_{14}$ & 0.0000 & 0.0000 & 0.0000 & 0.0002 \\
$c_{15}$ & 0.0000 & 0.0003 & 0.0001 & \\
\hline
\end{tabular}

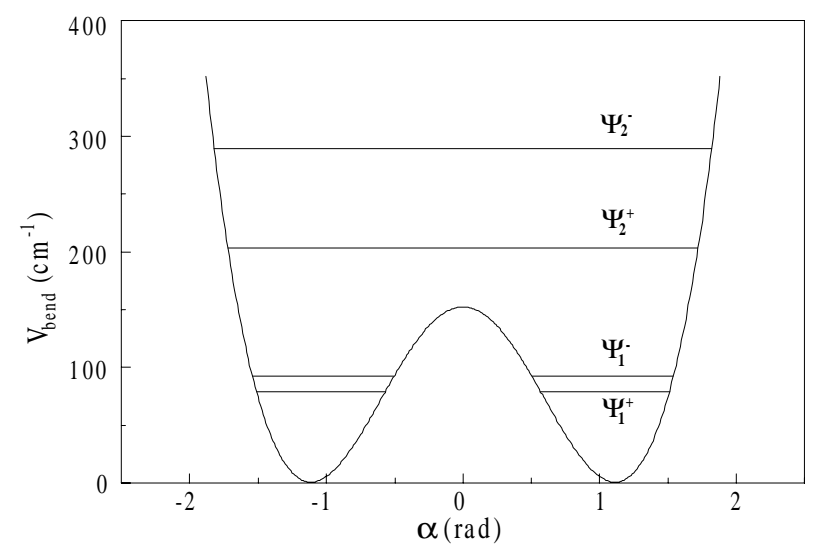

Figure 4. The first four energy levels obtained for the bending motion, along with the intermolecular potential energy surface.

region to tend to zero, the even and odd symmetry will have much more similar oscillatory characteristics, so their energy levels will be closer. At the other extreme, with the disappearing of the barrier, the levels will be splitted, and their behaviors will be like harmonic oscilators.

For the calculations of the intensities of the transitions we have used the following expression:

$$
\kappa=\frac{8 \pi^{3} N_{a}}{3 h c} v_{i j}\left(N_{i}-N_{j}\right)\left|<\psi_{i}\right| \hat{\mu}\left|\psi_{j}>\right|^{2}
$$

where $v_{\mathrm{ij}}$ is the frequency of the transition between the $\mathrm{i}$ and $\mathrm{j}$ states, $\mathrm{N}_{\mathrm{i}}$ and $\mathrm{N}_{\mathrm{j}}$ their populations and $\left|\left\langle\psi_{\mathrm{i}}|\hat{\mu}| \psi_{\mathrm{j}}\right\rangle\right|$ the dipole transition integral. The population of each state was calculated using Boltzmann law, and the dipole transition integral was obtained by:

$$
\begin{aligned}
& \left.\left.<\psi_{\mathrm{i}}|\hat{\mu}| \psi_{\mathrm{j}}>^{2}=<\psi_{\mathrm{i}}\left|\hat{\mu}_{\mathrm{x}}\right| \psi_{\mathrm{j}}\right\rangle^{2}+<\psi_{\mathrm{i}}\left|\hat{\mu}_{\mathrm{y}}\right| \psi_{\mathrm{j}}\right\rangle^{2}+ \\
& +<\psi_{\mathrm{i}}\left|\hat{\mu}_{\mathrm{z}}\right| \psi_{\mathrm{j}}>^{2} \\
& \hat{\mu}_{\mathrm{x}}=\mu_{\mathrm{HF}} \cos (\alpha) \\
& \hat{\mu}_{\mathrm{y}}=\mu_{\mathrm{HF}} \sin (\alpha) \\
& \hat{\mu}_{\mathrm{z}}=0
\end{aligned}
$$

The integrals given above were evaluated in an interval of $-\pi$ to $\pi$ radians, and the results are given in Table 4 , along with the values of $\mathrm{N}$ and $v$ used for every transition at two different temperatures, $10 \mathrm{~K}$ and $300 \mathrm{~K}$.

For the calculation of the stretching frequency, we have used the Dunham expansion ${ }^{27}$, performing the derivatives analytically with the Eq. 2. The values obtained were:

$$
\begin{aligned}
& v_{\text {stretc. harm }}=97.5964 \mathrm{~cm}^{-1} \\
& v_{\text {stretc. anarm }}=89.3787 \mathrm{~cm}^{-1}
\end{aligned}
$$

\section{Discussion}

Figure 4 shows the first four energy levels on the intermolecular energy surface for the $\mathrm{HF} \cdots \mathrm{Cl}$ bending motion of the HF...ClF complex. The levels are designated according to the symmetry of the wavefunctions as even $(+)$ or odd $(-)^{28}$. The two lowest eigenvalues are below the barrier top, with a splitting of $13.12 \mathrm{~cm}^{-1}$. Their wavefunctions are located in the two sides of the double well region, and exhibit a reasonable penetration into the barrier. The 

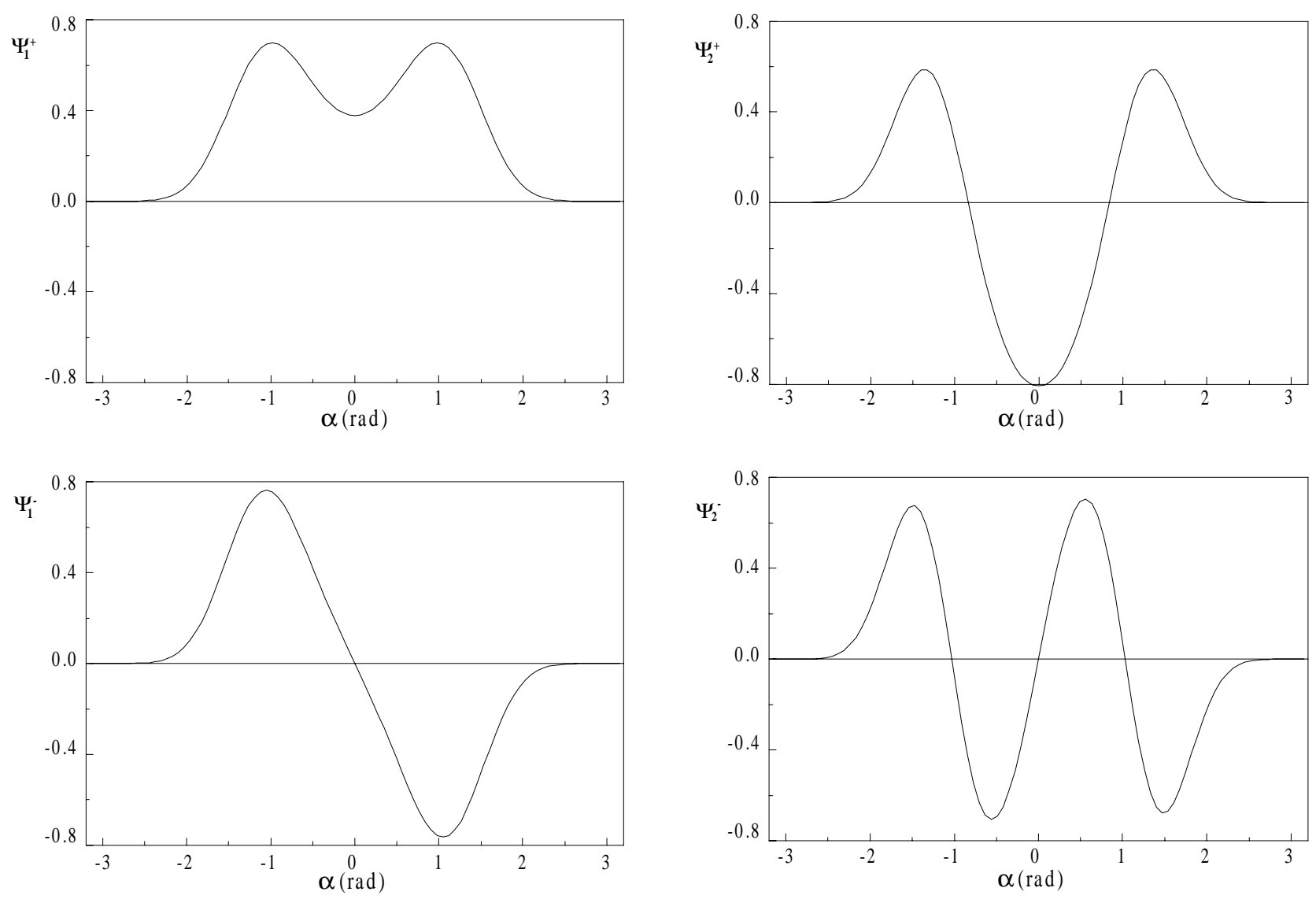

Figure 5. Eigenfunctions for the first four eigenvalues of the $\mathrm{HF} \cdots \mathrm{Cl}$ bending large amplitude vibration calculated by the variational method.

other two levels lie well above the barrier and have an accentuated separation.

Many van der Waals complexes, where tunneling motions occur, present more than one set of near-degenerate energy levels below the barrier, so the splitting of the transitions in the spectrum is generally observed. In the $\mathrm{HF} \cdots \mathrm{ClF}$ case, the situation is different. Just one doublet is below the energy barrier, and the other two levels are well above it, and exhibit characteristics very different from those of the doublet, so that the wavefunctions of these different sets of levels do not overlap in a satisfactory way. As a consequence, the transition from the doublet to the levels above of the barrier is almost forbidden, as can be seen in the second column of Table 4 . The dipole transition integral for the $1 \rightarrow 2$ transition is about one hundred times greater than the value for transitions between one level of the doublet ( 1 or 2$)$ and one of the levels above of the barrier ( 3 or 4 ). The $3 \rightarrow 4$ dipole transition integral is the most significant, i.e. three times greater than the doublet value. So, this system will present one intense absorption at $13.12 \mathrm{~cm}^{-1}$, due to the $1 \rightarrow 2$ transition, and another at $81.30 \mathrm{~cm}^{-1}$, due to the $3 \rightarrow 4$ transition (hot band). The transitions involving levels above of the barrier will prob- ably follow the harmonic oscillator rule, $\Delta v= \pm 1$, because for these levels, the presence of the barrier is just a small perturbation, so that the transitions would be allowed for adjacent levels.

We have calculated the intensity of the transitions including the temperature effect, using the Boltzmann distribution law to estimate the population of each level. At $10 \mathrm{~K}$, only the first two energy levels are significantly populated, resulting in the $1 \rightarrow 2$ transition to be the major one, because transitions of the levels below the barrier to those above it are almost forbidden owing to the low value of the transition dipole integral. Nevertheless, the $1 \rightarrow 3$ transition has a reasonable intensity in relation to $1 \rightarrow 2$ transition, because the former is ten times more energetic $\left(v_{i j}\right)$ than the latter. At $300 \mathrm{~K}$, it can be seen that the populations of the first four levels are significant, and in this situation, the first and second levels have almost the same population. As a consequence, the intensity of the 1 $\rightarrow 2$ transition is low (forbidden transition), and the intensity of the $3 b \rightarrow 4$ transition is the largest one.

Table 5 presents the intermolecular harmonic frequencies obtained for previous theoretical and experimental studies. The $1 \rightarrow 2$ transition of the HF... Cl bending mode 
Table 4. Dipole transition moments, relative populations, frequencies and intensities (in $\mathrm{km} / \mathrm{mol}$ ) for each possible transition of the bending motion in the $\mathrm{HF} \cdots \mathrm{ClF}$ complex, evaluated at two distinct temperatures.

\begin{tabular}{lcccccc}
\hline Transition $(\mathrm{i} \rightarrow \mathrm{j})$ & $\mathrm{K}\left\langle\varphi_{\mathrm{i}}|\hat{\mu}| \varphi_{\mathrm{j}}>\left.\right|^{2} /\left(\mathrm{D}^{2}\right)^{*}\right.$ & $\mathrm{vij}\left(\mathrm{cm}^{-1}\right)$ & $\mathrm{N}_{\mathrm{i}-\mathrm{Nj}(300 \mathrm{~K})}$ & $\kappa(300 \mathrm{~K})$ & $\mathrm{N}_{\mathrm{i}-\mathrm{N}_{\mathrm{j}}(10 \mathrm{~K})} \kappa(10 \mathrm{~K})$ \\
\hline $1-2$ & 0.128372 & 13.12 & 0.021357 & 0.090165 & 0.736978 & 3.111361 \\
$1-3$ & 0.001856 & 126.02 & 0.158854 & 0.093116 & 0.868489 & 0.509084 \\
$1-4$ & 0.000120 & 207.33 & 0.220645 & 0.013764 & 0.868489 & 0.054160 \\
$2-3$ & 0.000340 & 112.91 & 0.137497 & 0.013760 & 0.131511 & 0.012667 \\
$2-4$ & 0.002215 & 194.21 & 0.199288 & 0.214920 & 0.131511 & 0.141827 \\
$3-4$ & 0.452007 & 81.30 & 0.061791 & 5.691843 & 0 & 0 \\
\hline
\end{tabular}

* Dipole moment used for the HF molecule: $1.826 \mathrm{D}^{29}$.

Table 5. Ab initio (harmonic approximation) and experimental intermolecular frequencies (in $\mathrm{cm}^{-1}$ ) for the anti-H bonded minimum structure of the $\mathrm{HF} \cdots \mathrm{ClF}$ dimer.

\begin{tabular}{|c|c|c|c|c|}
\hline & $\mathrm{HF} \cdots \mathrm{ClF}$ stretching & $\mathrm{HF} \cdots \mathrm{Cl}$ bending & $\mathrm{F} \cdots \mathrm{ClF}$ in plane bending & $\mathrm{F} \cdots \mathrm{ClF}$ out of plane bending \\
\hline Novick et al. ${ }^{\mathrm{a}}$ & $100.5 \pm 2$ & - & \multicolumn{2}{|c|}{$170 \pm 20$} \\
\hline Rendell et al. ${ }^{\mathrm{b}}$ & 106 & 72 & 212 & 68 \\
\hline De Almeida et $a l{ }^{\mathrm{c}}$ & 105 & 78 & 237 & 90 \\
\hline
\end{tabular}

a - Ref. 20. Experimental work.

$\mathrm{b}$ - Ref. 21. Ab initio calculations with the TZP basis set using the coupled pair functional theory.

c - Ref. 22. Ab initio MP2 calculations with the $6-31+\mathrm{G}^{* *}$ basis set.

was not discussed in the experimental work, but theoretical $a b$ initio calculations ${ }^{21,22}$ reported frequency values of $72 \mathrm{~cm}^{-1}$ and $78 \mathrm{~cm}^{-1}$ in the harmonic approximation. It is of interest to note that these predicted frequencies are very similar to the value calculated in this work for the $3 \rightarrow 4$ transition. However, our value is for a hot band, not for the fundamental frequency.

Another point to be considered is the behavior of the wavefunctions shown in Fig. 5. It can be seen that when the $\alpha$ angle is near of $\pm \pi$ radians, the magnitude of the wavefunction falls quickly to zero. So, it reinforces our idea that the imposition of the boundary condition $\Psi( \pm \pi)=0$ is fully adequate to obtain the lowest energy levels for the bending motion of this weakly bound complex.

We have used the Dunham expansion to calculate the transition frequency of the intermolecular stretching motion. Our result for the harmonic frequency, $97.60 \mathrm{~cm}^{-1}$, is in excellent agreement with the experimental findings of $100 \pm 2 \mathrm{~cm}^{-1}$, and is better than the previously reported harmonic theoretical results of $106 \mathrm{~cm}^{-1}$ and $105 \mathrm{~cm}^{-1}$. However, van der Waals complexes in general present very accentuated anharmonicity. In fact, the calculated anharmonic correction to the vibrational motion decrease the transition frequency for the stretching motion to $89.38 \mathrm{~cm}^{-1}$.

\section{Conclusions}

The stretching and the $\mathrm{HF} \cdots \mathrm{Cl}$ bending vibrational motions in the HF...ClF van der Waals complex were studied using one dimensional approximations and a potential energy surface obtained by the $a b$ initio MP2 method using a very extended basis set. The bending motion corresponds to a vibration in the double well, with a barrier of $151 \mathrm{~cm}^{-1}$ (frozen core approximation), resulting in only one doublet with its energy below thar of the barrier. We have predicted an absorption at $13.12 \mathrm{~cm}^{-1}$ at $10 \mathrm{~K}$ due the $1 \rightarrow 2$ transition, and at $81.30 \mathrm{~cm}^{-1}$ at $300 \mathrm{~K}$ due the $3 \rightarrow 4$ transition. For the stretching motion, our predicted harmonic frequency is $97.60 \mathrm{~cm}^{-1}$, compared with $100 \pm 2 \mathrm{~cm}^{-1}$ determined experimentally. However, owing to the accentuated anharmonicity in this motion, the transition frequency is predicted to occur at $89.38 \mathrm{~cm}^{-1}$.

\section{Acknowledgments}

We wish to thank the Conselho Nacional de Desenvolvimento Científico e Tecnológico $(\mathrm{CNPq})$ for providing the research grants, and the Fundação de Amparo à Pesquisa no Estado de Minas Gerais (FAPEMIG), the Programa de Apoio ao Desenvolvimento Científico e Tecnológico (PADCT-Proc. № 62.0241/95.0) and the PróReitoria de Pesquisa (PRPq - UFMG) for supporting this project. 


\section{References}

1. Dyke, T.R.; Howard, B.J.; Klemperer, W. J. Chem. Phys. 1972, 56, 2442.

2. Bohac, E.J.; Miller, R. E. J. Chem. Phys. 1993, 99, 1537.

3. Chang, H.C.; Kemplerer, W. J. Chem Phys. 1993, 98, 9266.

4. Fraser, G.T. J. Chem. Phys. 1989, 90, 2097.

5. Kofranek, M.; Lischka, H.; Karpfen, A. Chem. Phys. 1988, 121, 137.

6. Althorpe, S.C.; Clary D.C. Chem. Phys. Letters 1991, 187, 345.

7. Bunker, P.R.; Epa, V.C.; Jensen, P.; Karpfen, A. J. Mol. Spectry. 1991, 146, 200.

8.Zhang, D.H.; Wu, Q.; Zhang, J.Z.H.; von Dirke, M.; Bacic, Z. J. Chem. Phys. 1995, 102, 2315.

9. Quack, M.; Suhm, M.A. J. Chem. Phys. 1991, 95, 28.

10. Necoechea, W.; Truhlar, D. Chem. Phys. 1996, 248, 182.

11. Resende, S.M.; De Almeida, W.B. J. Chem. Phys. 1995, 102, 4184.

12. Resende, S.M.; De Almeida, W.B. Chem. Phys. 1996, 206, 1.

13. Makarewicz, J.; Ha, T.; Bauder, A. J. Chem. Phys. 1993, 99, 3694.

14. Ha, T.; Makarewicz, J.; Bauder, A. J. Phys. Chem. 1993, 97, 11415.

15. Stockman, P.A.; Blake, G.A. Chem. Phys. Lett. 1993, 212, 298.
16. Tan, X.; Xu, L.; Tubergen, M.J.; Kuczkowski, R. J. Chem. Phys. 1994, 101, 6512.

17. Fraser, G.T.; Lovas, F.J.; Suenram., R.D.; Gillies, J.Z.; Gillies, C.W. Chem. Phys. 1992, 163, 91.

18. Bumgarner, R.E.; Suzuki, S.; Stockman, P.A.; Green, P.G.; Blake, G.A. Chem. Phys. Lett. 1991, 176, 123.

19. De Almeida, W.B.; Barker, D.A.; Hinchliffe, A. J. Chem. Phys. 1993, 99, 5917.

20. Novick, S.E.; Janda, K.; Klemperer, W. J. Chem. Phys. 1976, 65, 5115.

21. Rendell, A.P.L.; Bacskay, G.B.; Hush, N.S. J. Chem. Phys. 1987, 87, 535.

22. De Almeida, W.B.; Barker, D.A.; Hinchliffe, A.; Craw, J.S. Theochem 1993, 285, 277.

23. Pliego Jr, J.R.; Resende, S.M.; De Almeida, W.B. Theor. Chim. Acta. 1996, 93, 333.

24. Hobza, P.; Zahradnik, R. Chem. Rev. 1988, 88, 871.

25. Boys, S.F.; Bernardi, F. Mol. Phys. 1970, 19, 533.

26. Gamess, Schmidt, M.; Baldridge, K.; Boatz, J.; Elbert, S.; Gordon, M.; Jensen, J.; Koseki, S.; Matsunaga, N.; Nguyen, K.; Su, S.J.; Windus, T.; Dupuis, M.; Montgomery, J. J. Comput. Chem. 1993, 14, 1346.

27. Dunham, J.L. Phys. Rev. 1932, 41, 721.

28. Lewis, J.D.; Malloy, T.B.; Chao, T.H.; Laane, J. J. Mol. Structure 1972, 12, 427.

29. Hellwege, K.H. In Numerical Data and Functional Relationships in Science and Technology, Group II, Vol. 6, Molecular Constants; Landolt-Börnstein, Ed.; Springer-Verlag, Heidelberg, 1974. 